\section{As Yogi Berra and Bill Clinton Would Say}

I recently gave a lecture at a well-known graduate school of business, and I was struck by how much it was like a lecture I had given more than 10 years ago, when I was employed by a large national payor. On my last slide, entitled, "Déjà vu all over again: 90 s to 00s," the final line read: "This will be your lecture in 10 years—as we will still be dealing with this, you can borrow my slides."

Indeed, the pressures and tensions currently at work in our nation's health care system are much like those experienced in the early 1990s. Our nation's expenditures on health care could reach $\$ 3.6$ trillion in 2014 and could then account for $20 \%$ of the nation's gross domestic product. Large employers are again expressing substantial concern about the impact of providing health benefits at a high cost to their companies, in an era of global economy in which foreign competitors are not burdened with such costs. Cost concerns within the Medicare and Medicaid programs dominate public policy debate.

Nowhere in medicine is the concern about rising expenditures greater than in oncology. Large national private payors tell NCCN that oncology costs represent $12 \%$ of a typical payor's overall medical expense budget. Furthermore, these costs for cancer care are growing annually at a rate of $14 \%$, almost double the average growth of a plan's medical costs. One major national insurer has informed me that, in cancer care, the costs of drugs and biologics now exceed all hospital services for patients with cancer. Insurers and their main customers are again seeking to apply cost containment programs and are again even willing to do so in cancer care.

After some mid-1990s success in moderating the rate of rise of health care expenditures, how did we get back to the same pressure-filled environment? Well, to paraphrase Bill Clinton, "It's health care technology, stupid." Seen from a system standpoint, the modest and temporary success of the mid to late 1990s was achieved by decreasing or controlling provider reimbursement. For example, facility and professional levels of reimbursement for cardiac bypass services were cut in half. Now, not much "fat" is left on the provider side.

Instead, what is driving the costs of health care, system-wide and particularly in oncology, is the success of our nation's biomedical research in developing and introducing promising, innovative health care technologies (drugs, devices, procedures, and techniques). This is clearly evident in oncology, especially regarding drugs and biologic agents. These agents tend to have improved therapeutic indices associated with morespecific biologic targets and less toxicity. Thus, they are gradually transforming some cancers into chronic diseases. Additionally, more than 500 "promising" drugs and biologics are in phase I to III trials. The "technologic imperative" in medicine is at once a blessing and a threat.

How can the technologic imperative be managed to assure continued delivery of effective, high-quality care to patients in an efficient manner? Strict coverage policies coupled with preauthorization and use management are often draconian and usually address problems only at the outer percentiles of the bell-shaped curve. However, in this bell-shaped curve, the 80/20 rule does not apply. Management can be achieved through manipulation of reimbursement. However, in our overly complex, Rube-Goldberg-like reimbursement structure, incentives often are misaligned if not overtly contradictory to encouraging effective and efficient practice.

Consumer-driven health care holds promise and provides the advantage of informing and involving the patient to a much greater extent. But it also has been misused in the name of "choice," especially in oncology, in structuring co-pays, co-insurance, and deductibles that discourage patients from receiving some effective therapies. Finally, there is using guidelines and guidelines-derived measures to evaluate quality of care. The collaboration among CMS, NCCN, and ASCO on the 2006 Medicare Oncology Demonstration Program epitomized a cooperative model for achieving the most effective and efficient use of innovative and promising technologies in cancer care. With the participation of an informed patient, a similar system holds the best hope for mitigating the threat of technology and realizing its blessings.

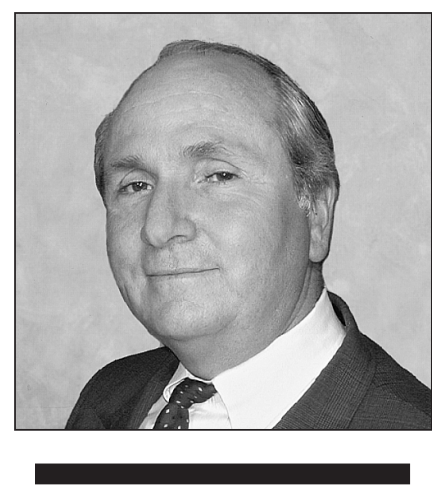

William T. McGivney, PhD William T. McGivney, PhD, is the Chief Executive Officer of the National Comprehensive Cancer Network (NCCN) and a recognized expert in coverage policy and drug and device regulatory policy. Before joining the NCCN in 1997, Dr. McGivney directed the Division of Health Care Technology at the American Medical Association and worked for Aetna Health Plans as Vice President for Clinical and Coverage Policy. Awarded the FDA Commissioner's Medal of Appreciation in 1989, Dr. McGivney has served on numerous national boards and committees. He earned his PhD at the University of North Carolina at Chapel Hill and completed a postdoctoral fellowship in the Department of Psychiatry at the Harvard Medical School.

The ideas and viewpoints expressed in this editorial are those of the author and do not necessarily represent any policy, position, or program of the NCCN. 